\title{
Theory of planned behavior as a conceptual framework for the willingness to self-isolate during the COVID-19 pandemic: A regional cross-sectional study
}

\author{
Rakhi Issrani* and Mohammad Khursheed Alam \\ Department of Preventive Dentistry, College of Dentistry, Jouf University, Sakaka, Kingdom of Saudi Arabia
}

Received 15 December 2020

Accepted 11 May 2021

\begin{abstract}
.
BACKGROUND: Due to an unavailability of a vaccine, one of the efficient methods to prevent the spread of the novel coronavirus (COVID-19) is by applying self-isolation (SI). Hence there is an urgent need to investigate the factors leading to an individuals' willingness to choose to self-isolate.

OBJECTIVES: The current study utilized the Theory of Planned Behavior (TPB) as a conceptual model and aimed to investigate the extent to which subjective norms, personal attitudes and perceived control influences an individual's willingness to self-isolate during COVID-19 risk.

METHOD: A cross-sectional study was performed on 800 Saudi respondents aged $\geq 18$ years by using a validated selfadministered questionnaire about factors related to willingness to self-isolate during COVID-19 pandemic risk based on the TPB. The effects of different variables on SI were analyzed by using ordinal logistic regression model.

RESULTS: A total of 756 (94.5\%) were completed and analyzed. Subjective norms and perceived control over the behavior significantly $(p<0.05)$ influenced the intention of willingness to self-isolate, while attitude was found to be insignificant. The odds of letting others to know about self COVID status were 2.40 times higher than not telling the neighbors or colleagues. A statistically significant difference $(p \leq 0.001)$ existed between males and females regarding the willingness to self-isolate. Similarly the odds of willingness to self-isolate with a presence of disabled person in family were 2.88 times higher than the absence of a disability in the family. Few recommendations for the policymakers that are needed to curb the spread of COVID-19 infection are also proposed.

CONCLUSION: The outcomes of study might be considered as an initial understanding of the factors that significantly influences an individual's willingness to SI when facing an unprecedented pandemic risk. Additionally, these factors provide a plan for policymakers to encourage citizens for self-isolation during pandemic infections.
\end{abstract}

Keywords: COVID-19, behavior, illness, risk, self-isolation

\footnotetext{
*Address for correspondence: Dr. Rakhi Issrani, Lecturer, Department of Preventive Dentistry, College of Dentistry, Jouf University, Sakaka, Kingdom of Saudi Arabia. E-mail: dr.rakhi. issrani@jodent.org.
}

\section{Introduction}

With the recent global novel coronavirus (COVID19) outbreak, public health authorities in all affected areas scrambled to impose the preventive measures that aimed at restricting its spread. At the beginning, 
the health-care providers were notified about the situations and were provided with the diagnostic protocols. But very soon it was being found that the infection had spread extensively [1]. This situation has become more alarming since there are no available vaccines, drug therapies or other aggressive treatments. Eventually, preventive interventions, including quarantine of entire towns/cities, strict contact tracing, cancellation of mass events and closing of borders with travel restrictions have been implemented by majority of the countries [2]. Of all the epidemic control measures that are implemented, isolation and quarantine are perceived as most important epidemic control measures of public health interventions [1].

The Saudi authorities had imposed a complete lockdown of the nation for more than 2 months (from March 2020 until end of April 2020) but from 26th April 2020, this complete lockdown was partially lifted with few hours' relaxation per day [3]. This incomplete lockdown indicates that henceforth the effective measure to prevent the spread of COVID-19 will be dependent on public behavior. Self-isolation (SI) is important at curtailing the spread of contagious infections and has been the focus of many studies based on different methods [4]. Unfortunately, voluntary SI strategies may be inconvenient for an individual, can cause social, psychological and economic distress or even lead to moral conflicts; thus, making it a controversial strategy [5].

Therefore, there is an urgent need to pursue the answers to the fundamental questions about what factors are associated with the willingness to self-isolate during the pandemic risk.

\subsection{Conceptual model}

The theory of planned behavior (TPB) was undertaken as the conceptual model for the current study because it seems to fit in situations where an individual do not perceive himself as having complete control over his behavior, as might occur in individual's intentions to self-isolate during COVID-19 pandemic [6]. This theory is one of the best-supported social psychological theories in relation to predicting human behavior and has been studied to explore a wide-range of behaviors in different populations and contexts $[2,4,7]$. The premise of TPB is that human beings make systematic use of available information and consider the consequences of their actions before engaging in a behavior [6]. With a strong intention to carry out a behavior, a person tends to perform

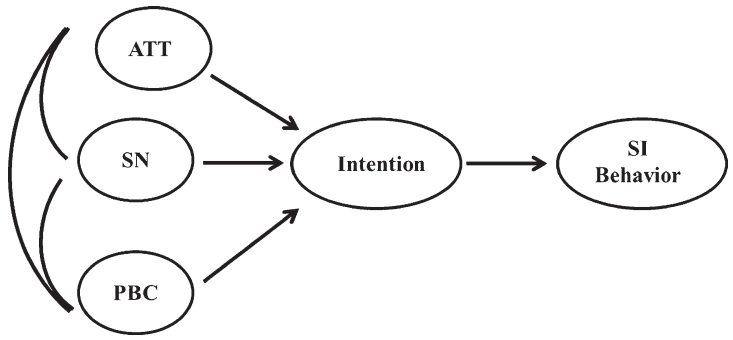

Fig. 1. Theoretical model of individuals' willingness to self-isolate based on the theory of planned behavior.

that behavior [6]. According to the TPB (as shown in Fig. 1), behavior is influenced by the following three factors, viz [4-6]

1. Attitudes toward the behavior (ATT) - reflecting an individual's belief about a particular behavior and his evaluation of those beliefs;

2. Subjective norms $(S N)$ with respect to the behavior - reflecting a person's beliefs regarding the expectations of significant others about performance of particular behaviors and an individual's motivation to comply with their significant others that can be religious leaders, family members, teachers, and friends; and

3. Perceived control over the behavior $(P B C)$ reflecting a person's perception regarding presence of any aid or obstacle in performing a given behavior.

The aforementioned reasons make TPB an appropriate model to study the factors related to SI during pandemic risk. Additionally, there are a lot of field where TPB has been used at a very few occasions only. One of them is willingness to self-isolate during COVID-19 pandemic. Therefore, the current study attempts at filling this research gap by considering these influencing factors of SI in the context of Saudi Arabia.

The present study aimed to explore an individual's intention to practice SI during COVID-19 infection based on TPB. Against this backdrop, this study was conducted with the following objectives:

1. To assess the willingness of general public of Sakaka, Saudi Arabia to self-isolate during COVID-19 pandemic infection;

2. To apply a regression method to determine the influence of SN, ATT and PBC on individuals' SI intention during a pandemic risk; and

3. Policy recommendations for the local government. 


\section{Methodology}

Ethical clearance from the respective institute (approval no. LCBE/11-02-42) was obtained and thereafter this cross-sectional survey study was conducted.

\subsection{Sample population, size and characteristics}

The population of Sakaka, KSA is nearly 243000 [8] that were taken into consideration while calculating the sample size. Assuming the response distribution to be $50 \%$ with $95 \%$ confidence interval and 5\% margin of error, the minimum effective sample size measured for this study survey was 384 . Therefore a total of 800 respondents were included to allow attrition and dropout.

\subsection{Study design and population}

This study was conducted by using a validated selfadministered questionnaire from 1st October 2020 to 1 st December 2020 among the general public including patients and their accompanying persons (e.g. patient's family members, friends, and relatives) attending the Outpatient Department of College of Dentistry, Jouf University. Other than this, the research was also conducted at the various community centers at Sakaka, KSA. Respondents were selected using a convenient sampling method. The target population was composed of adults of Sakaka city, aged $\geq 18$ years who understood English or Arabic language. Those who did not fulfil any of the aforementioned criteria were excluded from this study.

\subsection{Data collection tool}

The questionnaire was adapted from previous study with the permission of the authors [5]. The survey questionnaire was prepared in two language versions: English and Arabic (the national language of Saudi Arabia). The English version was prepared first that was later translated into Arabic language. The study tool was piloted with 30 randomly selected subjects from the study to determine the ability of participants to understand and answer the questionnaire provided along with determining an estimate of an average time required to complete the questionnaire. To ensure content validity of the questionnaire, two senior faculty members who are expertise in survey research re-assessed the validity of the variable scales. Based on expert opinions and the findings of pilot study, some modifications of the questionnaire were done prior to the actual survey. It was also noted that each survey could be completed in approximately 7 minutes.

\subsection{Procedures}

The selected and volunteering participants were requested to choose only one answer among the options provided. Before obtaining a verbal informed consent, the purpose of survey was briefed to them along with an assurance that the survey findings would be only published as an aggregate data maintaining the confidentiality of their personal information.

\subsection{Data analysis}

All data was analyzed using SPSS version 20.0 (IBM Corp., Armonk, NY, USA). Descriptive statistics (mean and standard deviations) was used to summarize the data related to quantitative variables. Following this, a correlation matrix was done to assess these influences and relationships in which all the studied variables were included. Subsequently, ordinal logistic regression model was used to determine the effects of SN, PBC and ATTs on SI. The significant values of the structural model are set to $p \leq 0.05$.

\section{Results}

Of the 800 questionnaires administered to all eligible participants, a total of 756 were completed and analyzed, giving a response rate of $94.5 \%$. Table 1 shows the studied variables along with the descriptive statistical results. The average age of the participants was 41.4 years (range 18 to 74 years). Of all the participants, $416(55.0 \%)$ were males and $340(45.0 \%)$ were females. Most of the respondents had a college education or above and were married. Regarding the socio-economic status, most of participants belonged to the middle class. The average FNSC was 1.4 that means at least one member per family was in need of special care. Regarding the statement 'How much comfortable were you during the current lockdown due to COVID-19 infection?' 286 (37.8\%) participants were 'very much' comfortable followed by 159 (21.0\%) participants who were 'little bit' comfortable whereas 41 (5.4\%) respondents were 'not at all' comfortable. 
Table 1

Descriptive statistics of variables $(N=756)$

\begin{tabular}{|c|c|c|c|c|}
\hline Variable & Indicators & Variable description & $n(\%)$ & $\overline{M e a n} \pm \mathrm{SD}$ \\
\hline \multirow[t]{2}{*}{ Gender } & \multirow[t]{2}{*}{ Q1. What is your gender? } & 1) Male & $416(55.0)$ & \multirow[t]{2}{*}{-} \\
\hline & & 2) Female & $340(45.0)$ & \\
\hline \multirow[t]{6}{*}{ Age } & \multirow[t]{6}{*}{ Q2. How old are you? } & 1) $18-27$ & $151(20.0)$ & \multirow[t]{6}{*}{$2.95 \pm 1.38$} \\
\hline & & 2) $28-37$ & $136(18.0)$ & \\
\hline & & 3) $38-47$ & $196(25.9)$ & \\
\hline & & 4) $48-57$ & $176(23.3)$ & \\
\hline & & 5) $58-67$ & $69(9.1)$ & \\
\hline & & 6) Older than 68 & $28(3.7)$ & \\
\hline \multirow[t]{6}{*}{ Education } & \multirow{6}{*}{$\begin{array}{l}\text { Q3. What is your highest level of } \\
\text { education? }\end{array}$} & 1) Primary school \& below & $103(13.6)$ & \multirow[t]{6}{*}{-} \\
\hline & & 2) Secondary school & $95(12.6)$ & \\
\hline & & 3) Bachelor & $370(48.9)$ & \\
\hline & & 4) Diploma & $109(14.4)$ & \\
\hline & & 5) Master & $78(10.3)$ & \\
\hline & & 6) $\mathrm{PhD}$ & $01(0.1)$ & \\
\hline \multirow[t]{4}{*}{ Marriage } & \multirow[t]{4}{*}{ Q4. Are you married? } & 1) No & $245(32.4)$ & \multirow[t]{4}{*}{-} \\
\hline & & 2) Yes & $301(39.8)$ & \\
\hline & & 3) Divorced & $154(20.4)$ & \\
\hline & & 4) Widowed & $56(7.4)$ & \\
\hline \multirow[t]{5}{*}{ Socioeconomic status (SS) } & \multirow{5}{*}{$\begin{array}{l}\text { Q5. What level of social and economic } \\
\text { status do you think you have? }\end{array}$} & 1) Upper level & $51(6.7)$ & \multirow[t]{5}{*}{$2.81 \pm 0.80$} \\
\hline & & 2) Middle and upper levels & $145(19.2)$ & \\
\hline & & 3) Middle level & $491(64.9)$ & \\
\hline & & 4) Middle and lower levels & $34(4.5)$ & \\
\hline & & 5) Lower level & $35(4.6)$ & \\
\hline \multirow[t]{5}{*}{ Self-isolation (SI) } & & (1) Very much & $286(37.8)$ & $2.39 \pm 1.31$ \\
\hline & during the current lockdown due to & (2) Fine to some extent & $124(16.4)$ & \\
\hline & COVID-19 infection? & (3) Uncertain & $146(19.3)$ & \\
\hline & & (4) Little bit & $159(21.0)$ & \\
\hline & & (5) Not at all & $41(5.4)$ & \\
\hline Attitudes toward the behavior & Q7. Do you agree or disagree with the & (1) Strongly disagree & $00(00)$ & $4.03 \pm 0.99$ \\
\hline (ATT) & government's mandatory isolation & (2) Disagree & $89(11.8)$ & \\
\hline & people during a COVID-19 infection? & (3) It does not matter & $96(12.7)$ & \\
\hline & & (4) Agree & $272(36.0)$ & \\
\hline & & (5) Strongly agree & $299(39.6)$ & \\
\hline Subjective norms with respect & Q8. If you were infected with a & (1) Absolutely not & $00(00)$ & $3.37 \pm 0.66$ \\
\hline to the behavior $(\mathrm{SN})^{*}$ & pandemic disease, would you let your & (2) No & $76(10.1)$ & \\
\hline & neighbors or colleagues know? & (3) Probably & $322(42.6)$ & \\
\hline & & (4) Absolutely & $358(47.1)$ & \\
\hline & Q9. How much do you trust the & (1) Strongly distrust & $00(00)$ & $3.98 \pm 0.89$ \\
\hline & infectious disease prevention & (2) Distrust & $62(8.2)$ & \\
\hline & information/text messages issued by & (3) Cannot say trust or distrust & $119(15.7)$ & \\
\hline & the health department? & (4) Trust & $342(45.2)$ & \\
\hline & & (5) Strongly trust & $233(30.8)$ & \\
\hline Perceived control over the & Q10. Do you think that COVID-19 & (1) Not serious at all & $37(4.9)$ & $3.24 \pm 0.83$ \\
\hline behavior $(\mathrm{PBC})^{* *}$ & infectious disease would have a serious & (2) Not too serious & $62(8.2)$ & \\
\hline & impact on you or your family? & (3) A little serious & $338(44.7)$ & \\
\hline & & (4) Very serious & $319(42.1)$ & \\
\hline & Q11. Are you worried about COVID-19 & (1) Not worried at all & $29(3.8)$ & $3.02 \pm 0.74$ \\
\hline & infections? & (2) Not too worried & $113(14.9)$ & \\
\hline & & (3) A little worried & $429(56.7)$ & \\
\hline & & (4) Very worried & $185(24.5)$ & \\
\hline & Q12. Do you have confidence that you & (1) No confidence & $23(3.0)$ & $3.57 \pm 0.94$ \\
\hline & can protect yourself and your family & (2) Little confidence & $79(10.4)$ & \\
\hline & during COVID-19 infections? & (3) Uncertain & $197(26.1)$ & \\
\hline & & (4) Some confidence & $359(47.5)$ & \\
\hline & & (5) Very confident & $98(13.0)$ & \\
\hline Community resources (CRs) & Q13. Do you agree or disagree that your & (1) Strongly disagree & $20(2.6)$ & $4.14 \pm 0.95$ \\
\hline & community has the resources (capi- & (2) Disagree & $29(3.8)$ & \\
\hline & tal/technology/materials/services,etc.) & (3) It does not matter & $87(11.5)$ & \\
\hline & to solve community problems? & (4) Agree & $311(41.1)$ & \\
\hline & & (5) Strongly agree & $309(40.9)$ & \\
\hline
\end{tabular}


Table 1

(Continued)

\begin{tabular}{|c|c|c|c|c|}
\hline Variable & Indicators & Variable description & $n(\%)$ & Mean \pm SD \\
\hline \multirow[t]{5}{*}{ Emergency services (ES) } & \multirow{5}{*}{$\begin{array}{l}\text { Q14. If an emergency happens, do you } \\
\text { agree or disagree that your community } \\
\text { can provide emergency services? }\end{array}$} & (1) Strongly disagree & $08(1.1)$ & \multirow[t]{5}{*}{$3.97 \pm 0.94$} \\
\hline & & (2) Disagree & $73(9.7)$ & \\
\hline & & (3) It does not matter & $119(15.7)$ & \\
\hline & & (4) Agree & $357(47.2)$ & \\
\hline & & (5) Strongly agree & $199(26.3)$ & \\
\hline \multirow{8}{*}{$\begin{array}{l}\text { Family members in need of } \\
\text { special care (FNSC) }\end{array}$} & \multirow{2}{*}{$\begin{array}{l}\text { Q15. Is there anyone under } 18 \text { in your } \\
\text { family? }\end{array}$} & (1) Yes & $503(66.5)$ & \multirow[t]{2}{*}{$1.33 \pm 0.47$} \\
\hline & & (2) No & $253(33.5)$ & \\
\hline & \multirow{2}{*}{$\begin{array}{l}\text { Q16. Is there anyone older than } 60 \text { in } \\
\text { your family? }\end{array}$} & (1) Yes & $544(72.0)$ & \multirow[t]{2}{*}{$4.14 \pm 0.94$} \\
\hline & & (2) No & $212(28.0)$ & \\
\hline & \multirow{2}{*}{$\begin{array}{l}\text { Q17. Is there anyone with a disability in } \\
\text { your family? }\end{array}$} & (1) Yes & $293(38.8)$ & \multirow[t]{2}{*}{$1.28 \pm 0.45$} \\
\hline & & (2) No & $463(61.2)$ & \\
\hline & \multirow{2}{*}{$\begin{array}{l}\text { Q18. Is there anyone with a chronic } \\
\text { disease in your family? }\end{array}$} & (1) Yes & $456(60.3)$ & \multirow[t]{2}{*}{$1.61 \pm 0.49$} \\
\hline & & (2) No & $300(39.7)$ & \\
\hline
\end{tabular}

*(Q8 = SNa $)(\mathrm{Q} 9=\mathrm{SNb}) * *(\mathrm{Q} 10=\mathrm{PBCa})(\mathrm{Q} 11=\mathrm{PBCb})(\mathrm{Q} 12=\mathrm{PBCc})$.

\subsection{SI and its influencing factors}

Overall, the mean score of SI in Sakaka city was 2.4 out of 5, which indicates people are between 'fine to some extent' and 'uncertain' regarding willingness to self-isolate. The results of correlation matrix are shown in Table 2 that depicts a significant association for 13 of the 14 indicators of SI especially SN, PBC and ATT that were positively related to SI.

The Pearson goodness-of-fit test showed that the model was not a good fit to the observed data, $\chi 2(724)=2785.73, p<0.001$. The deviance goodness-of-fit test illustrated that the model was not a good fit to the observed data, $\chi 2(724)=1373.26$, $p<0.001$. However, the Nagelkerke measure showed that the model explains $71.9 \%$ of the variance in the dependent. The final model significantly predicted the dependent variable over and above the interceptonly model, $\chi 2(28)=588.09, p<0.001$.

Subjective norms and PBC significantly $(p<0.05)$ influenced the intention of willingness to self-isolate, while ATT was found to be related insignificantly. The odds of letting others to know about self COVID status were 2.40 times higher than not telling the neighbors or colleagues. A statistically significant difference $(p=<0.001)$ existed between males and females regarding the willingness to self-isolate, with males demonstrating 2.58 times more willingness to self-isolate. Similarly the odds of willingness to self-isolate with a presence of disabled person in family were 2.88 times higher than the absence of a disability in the family. Table 3 shows the parameter estimates of ordinal linear regressions for willingness to self-isolate during the pandemic risks.

\section{Discussion}

The findings of the current research are evident to support the TPB as an efficient predictor of people's behavior for willingness to self-isolate during COVID-19 pandemic. Among the three influential factors, SN plays the most important role followed by PBC and ATT. This finding is consistent with the previous studies where $\mathrm{SN}$ and $\mathrm{PBC}$ were found to the better predictor of the said behavioral intentions although $\mathrm{PBC}$ variables were typically less important than SN [4, 5, 9-16]. In contrast, few of the previous studies opined the influences of ATT and PBC on establishing an intention to be stronger than the influence of SN [6, 17-24].

For SN, a significant result was observed where the respondents strongly agreed in letting the neighbors or colleagues know about an individual's being positive for COVID-19 infection. This behavior could be either due to individuals' fear that they might spread the disease to their dear ones or could be due to the possible social pressures because an individual who does not follow such normative actions receives blame from others and immediately becomes the public enemy $[25,26]$.

As shown in this study, an average attitude to willingly self-isolate during the pandemic risk might be attributed to the fact that individuals may believe that the spread of an infection is not reduced only by restricting themselves at home and avoiding gatherings but rather regularly washing hands using soap and water or with hand sanitizers, eating healthy foods and covering the nose and mouth while sneezing or coughing along with strictly following social distancing as suggested by WHO [27]. Also, the 


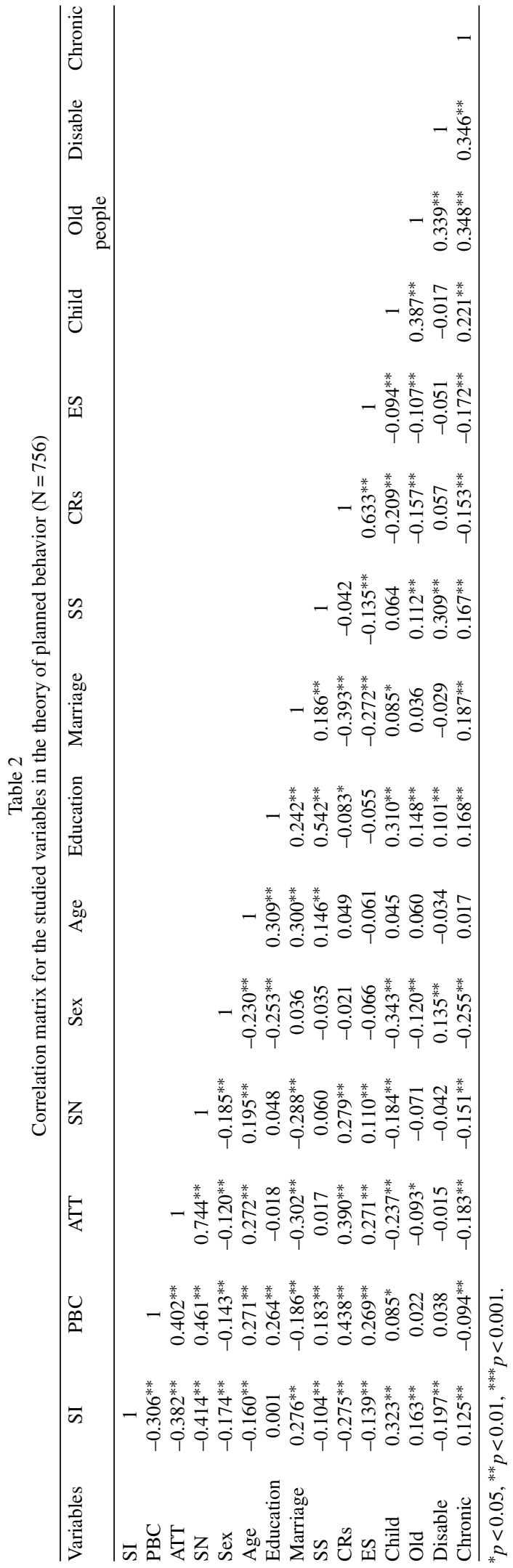

significance of the TPB factors for the prediction of behavior intention varies according to the target population and behavior [28].

This study further investigated the relationship between individual's age, gender, level of education, marital status, and economic status and found that younger respondents demonstrated a more positive intention for SI. These results were consistent with recent studies where the younger participants showed a positive intention towards the said behavior $[5,6,29]$. In the current study, gender had a significant difference on willingness to self-isolate with males showing more willingness as compared to the females. The crisis might aggravate gender inequality especially for working mothers as they might have suffered a severe physical and emotional distress from being overloaded with childcare due to school closure while do multitasking [16]. Additionally, the females might be depressed due to the pandemic that has lasted longer than anticipated. Similar results were found in previous studies where differences in behavioral changes between males and females was noted $[30,31]$ whereas another recent study found no significant difference between males and females in their behavioral change [5].

In the present study, a statistically significant difference was noticed between unmarried and widowed participants, with unmarried participants showing more willingness to self-isolate that is contradictory to the finding of a previous study where being married had a significant positive effect on SI [5]. This could be due to the fact that under risk circumstances, the herding behavior (i.e. referring to others' opinions in decision-making) of an unmarried individual could be more salient to minimize anxiety from uncertainty [32]. In the present study, willingness to self-isolate was seen to be reduced in upper social status, upper middle, middle and lower middle social status. It is a well-established fact that people belonging to such groups have less chances of social distancing due to cramped spaces which limits the resources to self-isolation, leading to more chances of infection. Diabetes and hypertension are also prevalent amongst such groups which complicate the outcomes once the person is infected [33]. In contrast to previous studies, the experience of the authors of this study had been different; in fact it was seen that high socio-economic status is a poor indicator for higher willingness for self-isolation [5].

Education and emergency services did not appear as a significant predictor variable for willingness to self-isolate in this study; in contrast with a recent 
Table 3

Parameter estimates

\begin{tabular}{|c|c|c|c|c|c|c|c|}
\hline \multirow[t]{2}{*}{ Variable } & \multirow[t]{2}{*}{ Estimate } & \multirow[t]{2}{*}{ Wald } & \multirow[t]{2}{*}{ df } & \multirow[t]{2}{*}{$p$-value } & \multirow[t]{2}{*}{$\begin{array}{l}\text { Odds } \\
\text { Ratio }\end{array}$} & \multicolumn{2}{|c|}{$\begin{array}{l}\text { 95\% Confidence } \\
\text { Interval }\end{array}$} \\
\hline & & & & & & $\begin{array}{l}\text { Lower } \\
\text { Bound }\end{array}$ & $\begin{array}{l}\text { Upper } \\
\text { Bound }\end{array}$ \\
\hline Age & -0.338 & 21.740 & 1 & $<0.001$ & 0.713 & -0.480 & -0.196 \\
\hline ATT & 0.083 & 0.392 & 1 & 0.531 & 1.087 & -0.177 & 0.343 \\
\hline $\mathrm{SNa}$ & 0.877 & 14.118 & 1 & $<0.001$ & 2.404 & 0.420 & 1.334 \\
\hline $\mathrm{SNb}$ & -0.677 & 18.365 & 1 & $<0.001$ & 0.508 & -0.987 & -0.367 \\
\hline $\mathrm{PBCa}$ & -0.570 & 11.165 & 1 & 0.001 & 0.566 & -0.904 & -0.236 \\
\hline $\mathrm{PBCb}$ & -0.443 & 9.312 & 1 & 0.002 & 0.642 & -0.728 & -0.158 \\
\hline $\mathrm{PBCc}$ & 0.236 & 4.961 & 1 & 0.026 & 1.267 & 0.028 & 0.444 \\
\hline CRs & -0.956 & 35.816 & 1 & $<0.001$ & 0.384 & -1.269 & -0.643 \\
\hline ES & 0.019 & 0.021 & 1 & 0.886 & 1.019 & -0.242 & 0.281 \\
\hline \multicolumn{8}{|l|}{ Gender } \\
\hline Males & 0.951 & 20.048 & 1 & $<0.001$ & 2.587 & 0.534 & 1.367 \\
\hline Females & $0^{\mathrm{a}}$ & & 0 & & 1.000 & & \\
\hline \multicolumn{8}{|l|}{ Education } \\
\hline Primary school \& below & -1.594 & 0.731 & 1 & 0.392 & 0.203 & -5.248 & 2.060 \\
\hline Secondary school & -0.310 & 0.028 & 1 & 0.867 & 0.734 & -3.934 & 3.315 \\
\hline Bachelor & -1.108 & 0.366 & 1 & 0.545 & 0.330 & -4.698 & 2.482 \\
\hline Diploma & -0.224 & 0.015 & 1 & 0.903 & 0.799 & -3.837 & 3.388 \\
\hline Master & -1.626 & 0.774 & 1 & 0.379 & 0.197 & -5.248 & 1.996 \\
\hline $\mathrm{PhD}$ & $0^{\mathrm{a}}$ & & 0 & & 1.000 & & \\
\hline \multicolumn{8}{|l|}{ Marriage } \\
\hline No & -1.890 & 16.703 & 1 & $<0.001$ & 0.151 & -2.796 & -0.984 \\
\hline Yes & -0.044 & 0.011 & 1 & 0.917 & 0.957 & -0.873 & 0.785 \\
\hline Divorced & -0.067 & 0.027 & 1 & 0.870 & 0.936 & -0.868 & 0.734 \\
\hline Widowed & $0^{\mathrm{a}}$ & & 0 & & 1.000 & & \\
\hline \multicolumn{8}{|l|}{ Social status } \\
\hline Upper level & -1.158 & 4.743 & 1 & 0.029 & 0.314 & -2.200 & -0.116 \\
\hline Middle and upper levels & -2.718 & 27.944 & 1 & $<0.001$ & 0.066 & -3.726 & -1.710 \\
\hline Middle level & -3.052 & 48.457 & 1 & $<0.001$ & 0.047 & -3.911 & -2.192 \\
\hline Middle and lower levels & -2.166 & 15.623 & 1 & $<0.001$ & 0.115 & -3.240 & -1.092 \\
\hline Lower level & $0^{\mathrm{a}}$ & & 0 & & 1.000 & & \\
\hline \multicolumn{8}{|c|}{ Is there anyone under 18 in your family? } \\
\hline Yes & -0.946 & 21.202 & 1 & $<0.001$ & 0.388 & -1.349 & -0.544 \\
\hline No & $0^{\mathrm{a}}$ & & 0 & & 1.000 & & \\
\hline \multicolumn{8}{|c|}{ Is there anyone older than 60 in your family? } \\
\hline Yes & -0.800 & 14.259 & 1 & $<0.001$ & 0.449 & -1.215 & -0.385 \\
\hline No & $0^{\mathrm{a}}$ & & 0 & & 1.000 & & \\
\hline \multicolumn{8}{|c|}{ Is there anyone with a disability in your family? } \\
\hline Yes & 1.059 & 23.224 & 1 & $<0.001$ & 2.883 & 0.628 & 1.489 \\
\hline No & $0^{\mathrm{a}}$ & & 0 & & 1.000 & & \\
\hline \multicolumn{8}{|c|}{ Is there anyone with a chronic disease in your family? } \\
\hline Yes & 0.235 & 1.390 & 1 & 0.238 & 1.264 & -0.155 & 0.625 \\
\hline No & $0^{\mathrm{a}}$ & & 0 & & 1.000 & & \\
\hline
\end{tabular}

${ }^{\mathrm{a}}$ This parameter is set to zero because it is redundant.

study where a higher educational level among the participants and the availability of emergency services had a significant positive influence on SI [5]. Conversely, community resources are not useful for SI which is in line with the findings from previous studies as well $[4,5]$. One possible explanation could be that the community will be more resilient if a community has more resources like food, money and technology that will eventually lead to an individual's less willingness to self-isolate because a person believes that the community will manage the risk related to an contagious infection.

For FNSC, the effects on SI of having a family member who has a disability or a chronic disease were positive, meaning that such individuals may have more willingness to self-isolate. This finding could be attributed to the fact that a family having a member who has any co-morbidity may be well aware of the medical emergencies with a better understanding of the dangers related to a pandemic. On the other 
hand, the effect of having a family member who is old or those in a family with a child was significant and negative, showing a lower willingness to self-isolate.

\subsection{Policy recommendations for the government}

It is highly appreciable the way the Saudi government has managed to curb the spread of the novel coronavirus. Early lockdown with phased interventions at various levels with restriction on mass gatherings and the population movement is a lustrous example of a bureaucracy which is socially responsible. A continuous creation of awareness amongst the community through recurring messages on mobile phones and innovative ideas to catch the attention of denizens has been an effective tool initiated by health care authorities of Saudi Arabia [34, 35]. Although the authorities in Saudi Arabia have left no stone unturned to achieve these goals but the findings of the current study identifies few important aspects that the government needs to take care when encouraging citizens to self-isolate during a pandemic situation. Firstly, an early warning system about pandemic emergencies should be provided that will significantly enhance the compliance with public health preventive measures like self-isolation and will subsequently improvise an individual's attitude to self-isolate during the pandemic risk. Although, the preventive measures like self-isolation and quarantine definitely impinges upon individuals' rights and freedoms other than imposing considerable economic and social distress as well but an early warning provided to the people will make them well-aware that an elimination of even a minute number of infected individuals from the general population is likely to be beneficial from the standpoint of community health.

Secondly, sufficient training regarding the better public services should be provided to citizens that will possibly reduce the difficulty of applying health behavior; otherwise, adherence to preventive measures may be low. The behavioral control improves when an individual is well-aware of the use of preventive items like face masks and sanitizers and confidently follows the preventive interventions.

It's needless to say that any organization with social responsibilities will find it difficult to manage the issues ranging from social, physical and mental health of the people; to the education, health care and daily needs. Through this study authors have tried to sum up all the factors that can challenge the government to enforce self-isolation amongst the general population of Saudi Arabia during the COVID-19 pandemic.

\section{Limitations}

The limitation is that since all the data were from one city of Northern part of Saudi Arabia, the findings may not be applicable for the population outside this geographic area and generalizations of the findings are, thus, limited.

\section{Conclusion}

The study provides a timely and meaningful understanding of the level of the public's behavior when facing a pandemic such that it can be used to target policy interventions needed to curtail the spread of COVID-19 infection. As informed by the health authorities, there is an urgent need to prepare for the second wave of the COVID-19 crisis; hence, the findings of this study might offer a significant reference point for follow-up longitudinal studies to assess an individual's short-term and long-term behavioral changes. Additionally, this study may add to the literature, as it explores notions of behavioral changes during a pandemic period.

\section{Author contributions}

Conceptualization: Dr. Rakhi Issrani, Dr. Mohammad Khursheed Alam. Methodology and formal analysis: Dr. Rakhi Issrani. Data curation: Dr. Rakhi Issrani. Literature search: Dr. Rakhi Issrani. Writing - original draft preparation: Dr. Rakhi Issrani. Writing - review and editing: Dr. Mohammad Khursheed Alam. Final approval of the version to be published: Dr. Rakhi Issrani, Dr. Mohammad Khursheed Alam.

\section{Conflict of interest}

The authors declare no conflict of interest

\section{Data availability}

The data set used in the current study will be made available on request from Dr. Rakhi Issrani; E-mail: dr.rakhi.issrani@jodent.org. 


\section{Funding}

The authors extend their appreciation to the Deanship of Scientific Research at Jouf University, Kingdom of Saudi Arabia, for funding this work through research grant no. CV-24-41 in April 2020.

\section{References}

[1] Day T, Park A, Madras N, Gumel A, Wu J. When is quarantine a useful control strategy for emerging infectious diseases? Am J Epidemiol. 2006;163:479-85.

[2] Lu W, Yuan L, Xu J, Xue F, Zhao B, Webster C. The psychological effects of quarantine during COVID-19 outbreak: Sentiment analysis of social media data. medRxiv [Preprint]. 2020 Available from: https://doi.org/10.1101/ 2020.06.25.20140426

[3] Algaissi AA, Alharbi NK, Hassanain M, Hashem AM. Preparedness and response to COVID-19 in Saudi Arabia: Building on MERS experience. J Infect Public Health. 2020;13:834-38.

[4] Adiyoso W, Wilopo W. Social distancing intentions to reduce the spread of COVID-19: The extended theory of planned behavior. Research Square [Preprint]. 2020 Available from: 10.21203/rs.3.rs-61524/v1

[5] Zhang X, Wang F, Zhu C, Wang Z. Willingness to selfisolate when facing a pandemic risk: Model, empirical test, and policy recommendations. Int J Environ Res Public Health. 2020;17:197. Available from: https://doi.org/ 10.3390/ijerph17010197

[6] Ko NY, Feng MC, Chiu DY, Wu MH, Feng JY, Pan SM. Applying theory of planned behavior to predict nurses' intention and volunteering to care for SARS patients in southern Taiwan. Kaohsiung J Med Sci. 2004;20:389-398.

[7] Lutz Sommer. The theory of planned behaviour and the impact of past behavior. International Business \& Economics Research Journal (IBER). 2011;10:91-110.

[8] Retrieved from https://en.wikipedia.org/wiki/Sakakah

[9] Lu Y, Zhou T, Wang B. Exploring Chinese users' acceptance of instant messaging using the theory of planned behavior, the technology acceptance model and the flow theory. Comput Human Behav. 2009;25:29-39.

[10] Lin CY, Cheung MKT, Hung ATF, Poon PKK, Chan SCC, Chan $\mathrm{CCH}$. Can a modified theory of planned behavior explain the effects of empowerment education for people with type 2 diabetes? Ther Adv Endocrinol Metab. 2020; 11:1-12.

[11] Chirayil EI, Thompson CL, Burney S. Predicting human papilloma virus vaccination and Pap smear screening intentions among young Singaporean women using the theory of planned behavior. SAGE Open. 2014;4:1-10.

[12] Alfahan A, Alhabib S, Abdulmajeed I, Rahman S, Bamuhair S. In the era of corona virus: Health care professionals' knowledge, attitudes, and practice of hand hygiene in Saudi primary care centers: A cross-sectional study. J Community Hosp Intern Med Perspect. 2016;6:321-51.

[13] Conner M, Norman P. Predicting health behaviour: Research and practice with social congnition model. Berkshire: Open University Press; 2006.

[14] Godin G, Kok G. The theory of planned behavior: A review of its applications to health- related behaviors. Am J Heal Promot. 1996;11:87-98.
[15] Babrow AS, Black DR, Tiffany ST. Beliefs, attitudes, intentions and a smoking-cessation program: A planned behavior analysis of communication campaign development. Health Commun. 1990;2:145-63.

[16] Bae SY, Chang PJ. The effect of coronavirus disease19 (COVID-19) risk perception on behavioral intention towards 'untact' tourism in South Korea during the first wave of the pandemic. Curr Issues Tour [Preprint]. 2020 Available from: https://doi.org/10.1080/13683500.2020. 1798895

[17] Zhou PP, Yu G, Kuang YQ, Huang XH, Li Y, Fu X, et al. Rapid and complicated HIV genotype expansion among high-risk groups in Guangdong Province, China. BMC Infect Dis. 2019;19:185.

[18] Cooke R, Dahdah M, Norman P, French DP. How well does the theory of planned behavior predict alcohol consumption? A systematic review and meta-analysis. Health Psychol Rev. 2016;10:148-67.

[19] Topa G, Moriano JA. Theory of planned behavior and smoking: Meta-analysis and SEM model. Subst Abuse Rehabil. 2010;1:23-33.

[20] Levin PF. Test of the Fishbein and Ajzen models as predictors of health care workers' glove use. Res Nurs Health. 1999;22:295-307.

[21] O'Boyle CA, Henly SJ, Larson E. Understanding adherence to hand hygiene recommendations: the theory of planned behavior. Am J Infect Control. 2001;29:352-60.

[22] Nash R, Edwards H, Nebauer M. Effect of attitudes, subjective norms and perceived control on nurses' intention to assess patients' pain. J Adv Nurs. 1993;18:941-7.

[23] Edwards HE, Nash RE, Najman JM, Yates PM, Fentiman BJ, Dewar A, et al. Determinants of nurses' intention to administer opioids for pain relief. Nurs Health Sci. 2001;3:149-59.

[24] Dilorio C. Neuroscience nurses' intentions to care for persons with HIV/AIDS. J Neurosci Nurs. 1997;29: $50-5$.

[25] Murray DR, Schaller M. Threat(s) and conformity deconstructed: Perceived threat of infectious disease and its implications for conformist attitudes and behavior. Eur $\mathbf{J}$ Soc Psychol. 2012;42:180-8.

[26] Jung W. Individual's freedom versus public health protection: The controversy over Corona bracelet for confirmed individuals. April 9, 2020. Available from: https://news. joins.com/article/23751091

[27] Siddiqui AA, Alshammary F, Amin J, Rathore HA, Hassan I, Ilyas M, et al. Knowledge and practice regarding prevention of COVID-19 among the Saudi Arabian population. Work (Reading, Mass.). 2020;66:767-75.

[28] Fishbein M, Ajzen I. Understanding attitudes and predicting social behavior. Englewood Cliffs, N.J.: Prentice-Hall; 1980.

[29] Tzeng HM. SARS infection control in Taiwan: Investigation of nurses' professional obligation. Outcomes Manag. 2003;7:186-93.

[30] Van der Weerd W, Timmermans DR, Beaujean DJ, Oudhoff J, van Steenbergen JE. Monitoring the level of government trust, risk perception and intention of the general public to adopt protective measures during the influenza A (H1N1) pandemic in the Netherlands. BMC Public Health. 2011;11:575.

[31] Klement C, Kissova R, Lengyelova V, Stipalova D, Sobotova Z, Galama JMD, et al. Human enterovirus surveillance in the Slovak Republic from 2001 to 2011. Epidemiol Infect. 2013;141:2658-62. 
[32] Banerjee AV. A simple model of herd behavior. Q J Econ. 1992;107:797-817.

[33] Geoffrey A, William FJ, David NC, Walter W, Patrick F. Using socio-economics to counter health disparities arising from the covid-19 pandemic. BMJ. 2020;369:m2149. doi: https://doi.org/10.1136/bmj.m2149.

[34] Prabhu N, Issrani R. Dilemma in the foreign lands during COVID-19: An outlook of expat health care professionals with a take on a social perspective. WORK: A Journal of Prevention, Assessment, and Rehabilitation. 2020;67: 779-82.

[35] Rathore HA, Hassan I, Ilyas M, Alam MK, Amin J, Alshammary F, Siddiqui AA. Psychological impact of COVID-19 lockdown on general population of Hail, Saudi Arabia. Medical Science. 2020;24:4682-8. 